\title{
Analisis potensi tanaman di sepanjang sumbu filosofis Keraton Yogyakarta sebagai sumber belajar biologi berbasis budaya
}

\author{
Arif Kurniawan \\ SMA Negeri 8 Yogyakarta, Jalan Sidobali Nomor 1 Muja Muju, Yogyakarta 55165 \\ arif.biologist@gmail.com
}

\begin{abstract}
Abstrak
Penelitian ini bertujuan untuk mempelajari potensi tanaman di sepanjang sumbu filosofis Keraton Yogyakarta sebagai sumber belajar biologi berbasis budaya. Jenis penelitian ini adalah penelitian kualitatif dengan teknik observasi, studi pustaka, dan dokumentasi. Analisis data dilakukan secara deskriptif. Hasil penelitian menunjukkan bahwa tanaman di lokasi tersebut terdiri dari 16 spesies yang dikelompokkan ke dalam 11 famili. Hasil analisis yang diperoleh menunjukkan bahwa fakta-fakta terkait tanaman di lokasi tersebut dapat digunakan sebagai sumber belajar biologi berbasis budaya pada tiga kompetensi dasar di kelas $\mathrm{X}$, yaitu pada KD 3.2-4.2 tentang berbagai tingkat keanekaragaman hayati, KD 3.3-4.3 tentang prinsip-prinsip klasifikasi makhluk hidup, dan KD 3.8-4.8 tentang klasifikasi tumbuhan. Objek tersebut telah memenuhi syarat sebagai objek yang dapat dimanfaatkan dan dikembangkan sebagai sumber belajar. Agar potensi sumber belajar tersebut lebih optimal, diperlukan upaya lebih lanjut untuk mengemas atau mengembangkan bahan ajar yang sesuai dengan karakteristik peserta didik
\end{abstract}

Kata kunci: sumbu filosofis Keraton Yogyakarta, sumber belajar biologi, pendidikan berbasis budaya

\section{Abstract}

This research aims to study the potential of plants along the philosophical axis of the Yogyakarta Palace as a source of culture-based biology learning. This type of research is qualitative research with observation techniques, literature study, and documentation. Data analysis was performed descriptively. The results showed that the plants in the location consisted of 16 species which were grouped into 11 families. The results of the analysis obtained show that the facts related to plants in the location can be used as a source of culture-based biology learning on three basic competencies in class X, namely in KD 3.2-4.2 about various levels of biodiversity, KD 3.3-4.3 about principles the classification of living things, and KD 3.8-4.8 concerning the classification of plants. The object has fulfilled the requirements as objects that can be utilized and developed as learning resources. So that the potential for learning resources is more optimal, further efforts are needed to package or develop teaching materials that are appropriate to the characteristics of students

Keywords: the philosophical axis of the Yogyakarta Palace, learning resources for biology, culture-based education

\section{PENDAHULUAN}

Pembelajaran biologi berbasis budaya merupakan salah satu konsekuensi logis dari diundangkannya pendidikan berbasis budaya di DIY. Dalam Undang-Undang Nomor 13 
Tahun 2012 tentang Keistimewaan DIY disebutkan bahwa salah satu kewenangan DIY adalah kewenangan mengatur kebudayaan. Undang-undang tersebut telah ditindaklanjuti dengan Peraturan Daerah Nomor 4 Tahun 2011 tentang Tata Nilai Budaya Yogyakarta, Peraturan Daerah Nomor 5 Tahun 2011 tentang Pengelolaan dan Penyelenggaraan Pendidikan Berbasis Budaya, dan beberapa turunan produk hukum sebagai acuan operasional. Dalam Peraturan Gubernur DIY Nomor 66 Tahun 2013 tentang Kurikulum Pendidikan Berbasis Budaya, pendidikan berbasis budaya dimaknai dalam tiga hal utama, yaitu pendidikan tentang budaya (budaya sebagai isi), pendidikan melalui pembudayaan (budaya sebagai metode), dan pendidikan dalam lingkungan budaya (budaya sebagai medan atau lingkungan pendidikan).

Menurut Peraturan Gubernur DIY Nomor 66 Tahun 2013, unsur-unsur budaya yang diajarkan/dikembangkan/diimplementasikan dalam kurikulum pendidikan berbasis budaya dikelompokkan menjadi tiga, yaitu nilai luhur, artefak, dan adat/kebiasaan. Jika ditelaah lebih lanjut, salah satu unsur budaya yang berpeluang untuk dapat diintegrasikan dalam pembelajaran biologi adalah artefak. Secara garis besar, artefak dapat dikelompokkan menjadi beberapa jenis karya seni-budaya, yaitu sastra, seni pertunjukan, seni lukis, seni kriya, busana, arsitektur, boga, dan olahraga/permainan. Dijelaskan lebih lanjut dalam Peraturan Daerah Nomor 4 Tahun 2011 tentang Tata Nilai Budaya Yogyakarta bahwa penataan ruang dan arsitektur merupakan salah dari 14 tata nilai budaya Yogyakarta.

Secara historis dan filosofis, nilai-nilai dasar penataan ruang Yogyakarta telah diletakkan dan disusun oleh Sultan Hamengku Buwono I dan dilanjutkan oleh para penerusnya. Salah satunya adalah sumbu filosofis yang berupa tata rakit bangunan, jalan, beserta tanaman. Sumbu filosofis merupakan warisan budaya saujana berbentuk bentang garis lurus antara Tugu Pal Putih, Keraton Yogyakarta, dan Panggung Krapyak. Dalam Peraturan Daerah Nomor 6 Tahun 2012 tentang Pelestarian Warisan Budaya dan Cagar Budaya dijelaskan bahwa tanaman merupakan salah satu dari tujuh elemen/unsur utama pembentuk kawasan yang harus dipertimbangkan dalam pelestarian kawasan warisan budaya dan kawasan cagar budaya. Jenis-jenis tanaman di sepanjang sumbu filosofis Keraton Yogyakarta inilah yang merupakan salah satu potensi sumber belajar untuk digunakan dalam pembelajaran biologi berbasis budaya.

Kurikulum pendidikan berbasis budaya mendasarkan pada semua peraturan perundangan nasional yang diperkaya dengan nilai budaya yang berkembang di DIY. Artinya kompetensi yang ingin dicapai, pelaksanaan pembelajaran dan manajemennya diperkaya dengan penambahan muatan dan metode yang digali dari kebudayaan daerah. Standar mutu 
pendidikan berbasis budaya mengacu pada standar nasional pendidikan, meliputi standar isi, standar proses, standar kompetensi lulusan, standar pendidik dan tenaga kependidikan, standar sarana dan prasarana, standar pengelolaan, standar pembiayaan, dan standar penilaian pendidikan. Dengan demikian, potensi tanaman di sepanjang sumbu filosofis Keraton Yogyakarta sebagai sumber belajar biologi berbasis budaya perlu dianalisis kesesuaiannya dengan kurikulum yang berlaku, yaitu Kurikulum 2013. Selain itu, perlu juga dianalisis dari aspek keterpenuhan syarat-syarat sumber belajar.

Penelitian ini bertujuan untuk mempelajari potensi tanaman di sepanjang sumbu filosofis Keraton Yogyakarta sebagai sumber belajar biologi berbasis budaya. Hasil penelitian ini diharapkan dapat memberikan informasi tentang potensi tanaman di sepanjang sumbu filosofis Keraton Yogyakarta sebagai sumber belajar biologi berbasis budaya. Dengan demikian, guru-guru biologi di Daerah Istimewa Yogyakarta dapat mendukung pelaksanaan pendidikan berbasis budaya secara nyata dalam bentuk pembelajaran biologi kontektual berbasis budaya Yogyakarta.

\section{METODE}

Penelitian ini dilaksanakan pada bulan Agustus 2019. Jenis penelitian ini adalah penelitian kualitatif yang dilakukan melalui kegiatan analisis potensi sumber belajar. Analisis potensi sumber belajar dilakukan melalui analisis kurikulum dengan melihat kesesuaian sumber belajar dengan kurikulum yang berlaku, yaitu Kurikulum 2013. Teknik observasi dan studi pustaka digunakan untuk mengumpulkan data berupa fakta-fakta tentang tanaman di sepanjang sumbu filosofis Keraton Yogyakarta, sedangkan dokumentasi untuk mengumpulkan data berkaitan dengan standar isi mata pelajaran biologi dalam Kurikulum 2013. Data yang didapatkan selanjutnya dianalisis secara deskriptif.

\section{HASIL DAN PEMBAHASAN}

Tanaman di sepanjang sumbu filosofis Keraton Yogyakarta terdiri dari 16 spesies. Keenam belas spesies tersebut terbagi ke dalam 11 famili, yaitu Anacardiaceae, Annonaceae, Arecaceae, Lecythidaceae, Leguminosae, Magnoliaceae, Moraceae, Myrtaceae, Rubiaceae, Rutaceae, dan Sapotaceae. Anacardiaceae merupakan famili yang paling banyak spesiesnya, yaitu Mangifera foetida, Mangifera odorata, dan Mangifera indica. Ketiganya berasal dari genus yang sama, yaitu Mangifera. Famili terbesar ke dua adalah Myrtaceae, tersusun oleh dua spesies dari genus Syzygium, yaitu Syzygium malaccense dan Syzygium pycnanthum. 
Tabel 1. Komposisi tanaman di sepanjang sumbu filosofis Keraton Yogyakarta

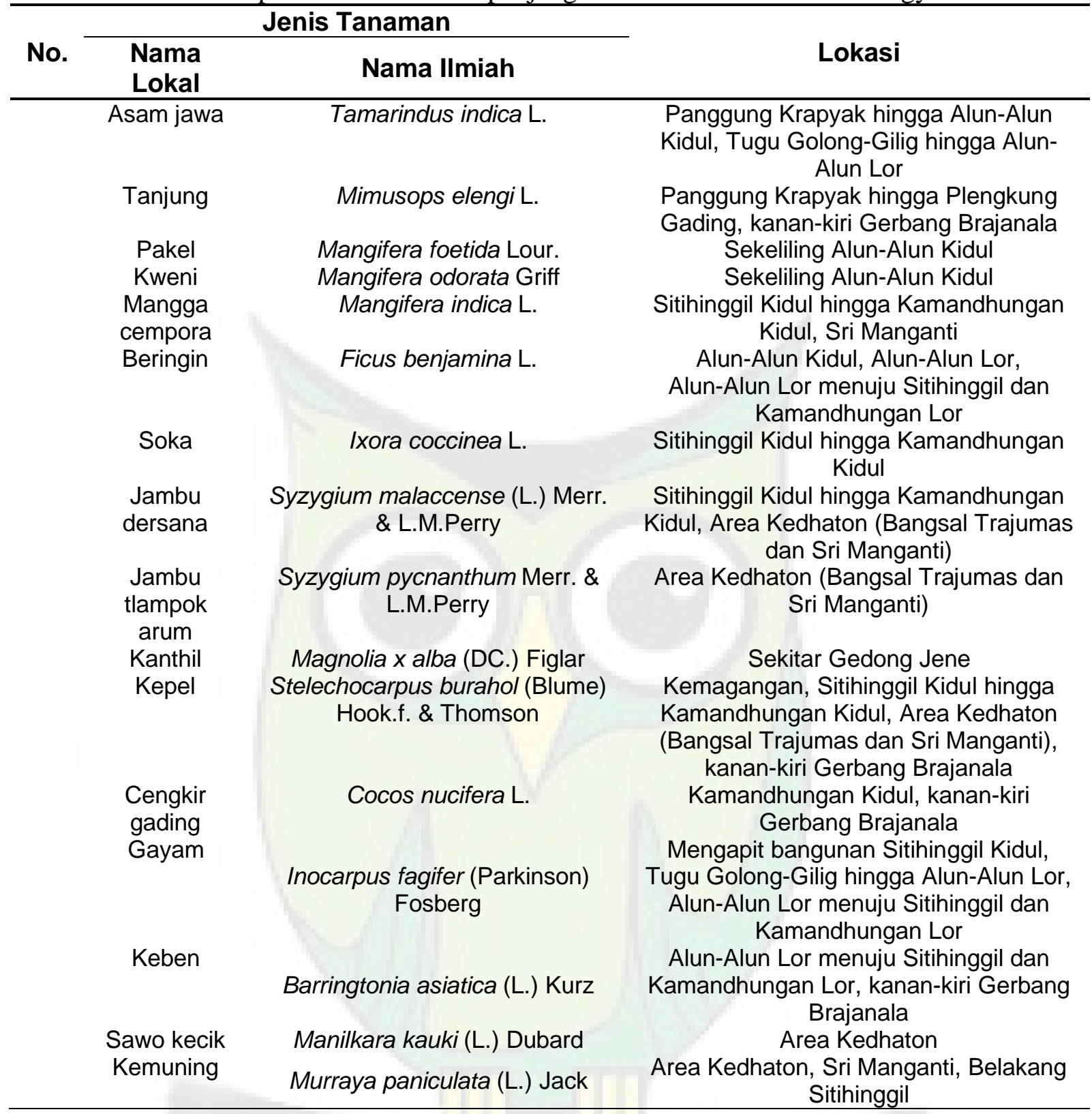

Kesesuaian potensi tanaman di sepanjang sumbu filosofis Keraton Yogyakarta sebagai sumber belajar biologi berbasis budaya pada Kurikulum 2013 tersaji dalam tabel 2. 
Tabel 2. Kesesuaian potensi tanaman di sepanjang sumbu filosofis Keraton Yogyakarta sebagai sumber belajar biologi berbasis budaya dengan Kurikulum 2013

\begin{tabular}{|c|c|c|c|}
\hline $\begin{array}{l}\text { Objek dan } \\
\text { Gejala yang } \\
\text { Dicermati }\end{array}$ & $\begin{array}{c}\text { Potensi yang Dapat Digunakan } \\
\text { untuk Belajar }\end{array}$ & & Kompetensi Dasar \\
\hline $\begin{array}{l}\text { Variasi morfologi } \\
\text { pada pakel, kweni, } \\
\text { dan mangga } \\
\text { cempora serta } \\
\text { jambu dersana } \\
\text { dan jambu } \\
\text { tlampok arum }\end{array}$ & $\begin{array}{c}\text { Fakta: } \\
\text { Pakel, kweni, dan mangga cempora } \\
\text { adalah contoh keanekaragaman jenis } \\
\text { dari genus Mangifera } \\
\text { Jambu dersana dan jambu tlampok } \\
\text { arum adalah contoh keanekaragaman } \\
\text { jenis dari genus Syzygium } \\
\text { Persoalan Biologi: } \\
\text { Apa yang dimaksud dengan } \\
\text { keanekaragaman jenis? }\end{array}$ & 4.2 & $\begin{array}{c}\text { Menganalisis berbagai tingkat } \\
\text { keanekaragaman hayati di } \\
\text { Indonesia beserta ancaman dan } \\
\text { pelestariannya } \\
\text { Menyajikan hasil observasi } \\
\text { berbagai tingkat } \\
\text { keanekaragaman hayati di } \\
\text { Indonesia dan usulan upaya } \\
\text { pelestariannya }\end{array}$ \\
\hline $\begin{array}{c}\text { Tanaman di } \\
\text { sepanjang sumbu } \\
\text { filosofis Keraton } \\
\text { Yogyakarta } \\
\text { disusun oleh } 16 \\
\text { spesies yang } \\
\text { terbagi ke dalam } \\
11 \text { famili }\end{array}$ & $\begin{array}{c}\text { Fakta: } \\
\text { Sebanyak } 16 \text { spesies tanaman di } \\
\text { sepanjang sumbu filosofis Keraton } \\
\text { Yogyakarta memiliki nama ilmiah dan } \\
\text { kategori takson tertentu } \\
\text { Persoalan Biologi: } \\
\text { Bagaimanakah urutan kategori } \\
\text { taksonomi dari yang kingdom hingga } \\
\text { spesies? } \\
\text { Bagaimanakah aturan tata nama } \\
\text { binomial makhluk hidup? }\end{array}$ & 3.3 & $\begin{array}{l}\text { Menjelaskan prinsip-prinsip } \\
\text { klasifikasi makhluk hidup dalam } \\
\text { lima kingdom } \\
\text { Menyusun kladogram } \\
\text { berdasarkan prinsip-prinsip } \\
\text { klasifikasi makhluk hidup }\end{array}$ \\
\hline $\begin{array}{c}\text { Tanaman di } \\
\text { sepanjang sumbu } \\
\text { filosofis Keraton } \\
\text { Yogyakarta } \\
\text { disusun oleh } 16 \\
\text { spesies yang } \\
\text { terbagi ke dalam } \\
11 \text { famili }\end{array}$ & $\begin{array}{l}\text { Fakta: } \\
\text { Sebanyak } 16 \text { spesies tumbuhan di } \\
\text { sepanjang sumbu filosofis Keraton } \\
\text { Yogyakarta memiliki ciri-ciri yang } \\
\text { berbeda, seperti pada bentuk batang, } \\
\text { kulit batang, tipe percabangan, } \\
\text { bentuk kanopi, dan bentuk daunnya } \\
\text { Persoalan Biologi: } \\
\text { Bagaimanakah klasifikasi } 16 \text { spesies } \\
\text { tanaman di sepanjang sumbu filosofis } \\
\text { Keraton Yogyakarta berdasarkan ciri- } \\
\text { ciri batang dan daunnya? }\end{array}$ & 4.8 & $\begin{array}{c}\text { Mengelompokkan tumbuhan ke } \\
\text { dalam divisio berdasarkan ciri- } \\
\text { ciri umum, serta mengaitkan } \\
\text { peranannya } \\
\text { dalam kehidupan } \\
\text { Menyajikan laporan hasil } \\
\text { pengamatan dan analisis } \\
\text { fenetik dan filogenetik } \\
\text { tumbuhan serta peranannya } \\
\text { dalam kehidupan }\end{array}$ \\
\hline
\end{tabular}

Berdasarkan Peraturan Menteri Pendidikan dan Kebudayaan Republik Indonesia Nomor 37 Tahun 2018 tentang Perubahan Atas Peraturan Menteri Pendidikan dan Kebudayaan Nomor 24 Tahun 2016 tentang Kompetensi Inti dan Kompetensi Dasar Pelajaran pada Kurikulum 2013 pada Pendidikan Dasar dan Pendidikan Menengah, tanaman di sepanjang sumbu filosofis Keraton Yogyakarta dapat digunakan sebagai sumber belajar biologi berbasis budaya pada tiga kompetensi dasar di kelas X, yaitu pada KD 3.2-4.2 tentang berbagai tingkat keanekaragaman hayati, KD 3.3-4.3 tentang prinsip-prinsip klasifikasi makhluk hidup, dan KD 3.8-4.8 tentang klasifikasi tumbuhan. 
Kriteria tanaman di sepanjang sumbu filosofis Keraton Yogyakarta sebagai objek yang dapat dimanfaatkan dan dikembangkan sebagai sumber belajar mengacu pada syarat-syarat sumber belajar, yaitu 1) kejelasan potensi, 2) kesesuaian dengan tujuan belajar, 3) kejelasan sasaran, 4) kejelasan informasi yang dapat diungkap, 5) kejelasan pedoman eksplorasi, dan 6) kejelasan perolehan yang diharapkan (Djohar, 1987 dalam Suratsih, 2010). Tanaman di sepanjang sumbu filosofis Keraton Yogyakarta telah memenuhi syarat sebagai sumber belajar sesuai kriteria tersebut. Kejelasan potensi tanaman di sepanjang sumbu filosofis Keraton Yogyakarta sebagai sumber belajar biologi ditunjukkan dengan adanya sejumlah fakta maupun permasalahan yang relevan. Selain itu, objek dan permasalahan tersebut juga sesuai dengan standar isi kurikulum 2013. Hal ini juga menunjukkan adanya kesesuaian dengan tujuan belajar. Sasaran sumber belajar ini juga jelas, yaitu objeknya yang konkret, yaitu tanaman di sepanjang sumbu filosofis Keraton Yogyakarta dan subjek belajarnya, yaitu siswa SMA kelas X. Informasi yang dapat diungkap dari sumber belajar ini adalah informasi berupa fakta-fakta berkenaan dengan tanaman di sepanjang sumbu filosofis Keraton Yogyakarta yang sesuai dengan materi biologi. Pedoman eksplorasi juga jelas karena informasi-informasi tersebut diperoleh melalui pendekatan ilmiah. Sedangkan perolehan yang diharapkan dari sumber belajar ini adalah pembelajaran biologi berbasis budaya Yogyakarta yang lebih kontekstual akan dapat meningkatkan pengetahuan, sikap maupun keterampilan siswa.

\section{SIMPULAN}

Tanaman di sepanjang sumbu filosofis Keraton Yogyakarta terdiri dari 16 spesies yang dikelompokkan ke dalam 11 famili. Tanaman tersebut dapat digunakan sebagai sumber belajar biologi berbasis budaya pada tiga kompetensi dasar di kelas X, yaitu pada KD 3.2-4.2 tentang berbagai tingkat keanekaragaman hayati, KD 3.3-4.3 tentang prinsip-prinsip klasifikasi makhluk hidup, dan KD 3.8-4.8 tentang klasifikasi tumbuhan. Objek tersebut telah memenuhi syarat sebagai objek yang dapat dimanfaatkan dan dikembangkan sebagai sumber belajar. Agar potensi sumber belajar tersebut lebih optimal, diperlukan upaya lebih lanjut untuk mengemas atau mengembangkan bahan ajar yang sesuai dengan karakteristik peserta didik.

\section{REFERENSI}

Peraturan Daerah Provinsi Daerah Istimewa Yogyakarta Nomor 4 Tahun 2011 tentang Tata Nilai Budaya Yogyakarta 
Peraturan Daerah Provinsi Daerah Istimewa Yogyakarta Nomor 5 Tahun 2011 tentang Pengelolaan dan Penyelenggaraan Pendidikan Berbasis Budaya

Peraturan Daerah Provinsi Daerah Istimewa Yogyakarta Nomor 6 Tahun 2012 tentang Pelestarian Warisan Budaya dan Cagar Budaya

Peraturan Gubernur Daerah Istimewa Yogyakarta Nomor 66 Tahun 2013 tentang Kurikulum Pendidikan Berbasis Budaya

Peraturan Menteri Pendidikan dan Kebudayaan Republik Indonesia Nomor 37 Tahun 2018 tentang Perubahan Atas Peraturan Menteri Pendidikan dan Kebudayaan Nomor 24 Tahun 2016 tentang Kompetensi Inti dan Kompetensi Dasar Pelajaran pada Kurikulum 2013 pada Pendidikan Dasar dan Pendidikan Menengah

Suratsih. 2010. Pengembangan Modul Pembelajaran Biologi Berbasis Potensi Lokal dalam Kerangka Implementasi KTSP SMA di Yogyakarta. Yogyakarta: Lembaga Penelitian UNY

Undang-Undang Nomor 13 Tahun 2012 tentang Keistimewaan DIY 